\title{
Thyroid Follicular Adenoma with Tracheal Stenosis
}

\author{
Takeshi Kusunoki ${ }^{1, *}$, and Ryo Wada ${ }^{2}$ \\ ${ }^{1}$ Department of Otorhinolaryngology, Juntendo University of Medicine, Shizuoka Hospital, Japan \\ ${ }^{2}$ Department of Pathology, Juntendo University of Medicine, Shizuoka Hospital, Japan
}

*Corresponding authors: Takeshi Kusunoki, Department of Otorhinolaryngology, Juntendo University of Medicine, Shizuoka Hospital, 1129 Nagaoka Izunokuni-shi, Shizuoka 410-2295, Japan, Fax: +81-55-948-5088; E-mail: ttkusunoki001@aol.com

Received: 20 Jul, 2021 | Accepted: 03 Aug, 2021 | Published: 12 Aug, 2021

Citation: Kusunoki T, Wada R (2021) Thyroid Follicular Adenoma with Tracheal Stenosis. J Clin Case Stu 6(4): dx.doi.org/10.16966/24714925.231

Copyright: (C) 2021 Kusunoki T, et al. This is an open-access article distributed under the terms of the Creative Commons Attribution License, which permits unrestricted use, distribution, and reproduction in any medium, provided the original author and source are credited.

\section{Abstract}

Some cases of thyroid malignant tumors and thyroid lymphoma were reported to have caused tracheal stenosis and choking. Benign thyroid tumors with dyspnea due to tracheal stenosis are very rare. We experienced a benign thyroid tumor that caused tracheal stenosis and dyspnea. In the preoperative $\mathrm{CT}$, there was tracheal stenosis due to enlarged bilateral thyroid lobes and the width of the stenotic lumen was $7 \mathrm{~mm}$. Subtotal thyroidectomy improved the dyspnea. Postoperative histopathologic examination confirmed follicular adenoma without malignant lesions or chronic thyroiditis. On postoperative CT, the tracheal stenosis had improved and the lumen had increased to $15 \mathrm{~mm}$. The above findings would suggest that it should be keep in mind that even benign thyroid tumors with tracheal stenosis of less than $7 \mathrm{~mm}$ in the lumen have the possibility of causing dyspnea.

Keywords: Follicular adenoma; Tracheal stenosis; Dyspnea

\section{Introduction}

Thyroid diseases with airway stenosis caused by cancer and lymphoma have been reported $[1,2]$. We previously presented that a case of a huge malignant lymphoma with chronic thyroiditis that cause dyspnea due to tracheal stenosis [3]. Benign thyroid tumors with dyspnea due to tracheal stenosis are exceedingly rare [4]. However, we recently experienced a benign thyroid tumor with dyspnea due to tracheal stenosis and performed subtotal thyroidectomy. This report describes the clinical findings, imaging examination, operation and postoperative progress and some considerations by referring to various studies.

\section{Case Report}

\section{Patient}

75 year's old, male, Japanese

\section{Chief complaint}

Dyspnea

\section{Past history}

Ten years ago, he suffered a traumatic injury to his upper right limb that required amputation, during which a tracheotomy was performed to secure the airway under general anesthesia. This tracheostomy was closed after the operation.

One month ago, surgery for a ruptured Achilles tendon was performed under general anesthesia by oral intubation in another hospital, and the postoperative progress was good.

\section{Current medical history}

Four days ago, dyspnea with wheezing, cough, and fever appeared. That hospital diagnosed the condition as septic shock with pneumonia and introduced him to the department of emergency medicine in our hospital. At the first visit to our hospital, CT (Figure 1) revealed severe pneumonia and tracheal stenosis with diffuse swelling of the bilateral thyroid lobes. The stenosis decreased the width of the lumen to $7 \mathrm{~mm}$. The department of emergency medicine performed orotracheal intubation and administered antibiotics moreover, this department consulted our department of otorhinolaryngology. We tried tracheotomy to keep the air way patent and thyroid biopsy. The histological findings of the thyroid biopsy showed no cancer, lymphoma or chronic thyroiditis. At the time of the initial thyroid examination, thyroid functions were almost within normal ranges freeT3 $2.5 \mathrm{pg} / \mathrm{ml}$ (normal range: $2.4-4.5 \mathrm{pg} / \mathrm{ml}$ ), free $\mathrm{T} 41.8 \mathrm{ng} / \mathrm{dL}$ (normal range: 1.0 $1.7 \mathrm{ng} / \mathrm{dL}$ ), TSH0.09 $\mu \mathrm{IU} / \mathrm{ml}$ (normal range:0.56-4.3 $\mu \mathrm{IU} / \mathrm{ml}$ ). In the anti-thyroid autoantibodies, the microsome test (normal range: 100 times or less) and the thyroglobulin test (normal range: 100 times or less) were both less than 100 times. The high value of thyroglobulin was $107.00 \mathrm{ng} / \mathrm{ml}$ (normal range:0-33.70ng/ml). Soluble interleukin-2 receptor as a tumor marker of the lymphoma showed $280 \mathrm{U} / \mathrm{ml}$ (normal range 122-496U/ml).

\section{Surgical findings}

After the septic shock and pneumonia improved, he underwent subtotal thyroidectomy with preservation of the bilateral upper thyroid poles. The postoperative progress was good, and there was no hemorrhage or vocal cord paralysis, clinical finding of tracheomalacia 

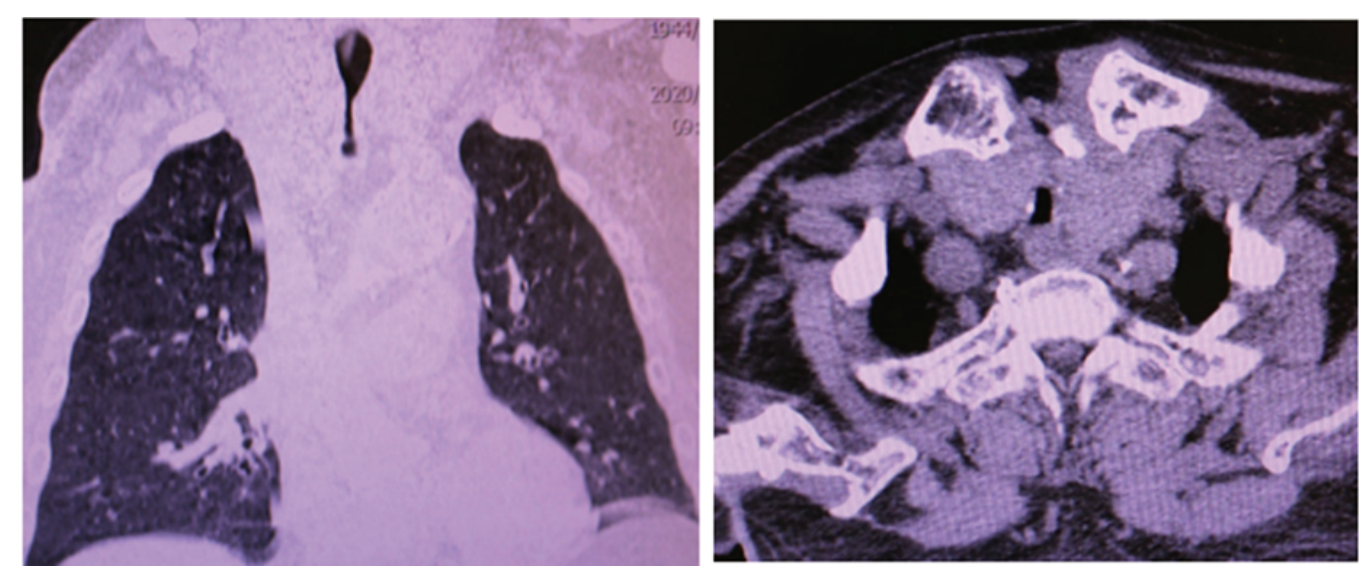

Figure 1: Preoperative CT showed severe pneumonia (left) and tracheal stenosis due to enlarged bilateral thyroid lobes (right). This stenosis decreased the width of the lumen to $7 \mathrm{~mm}$.

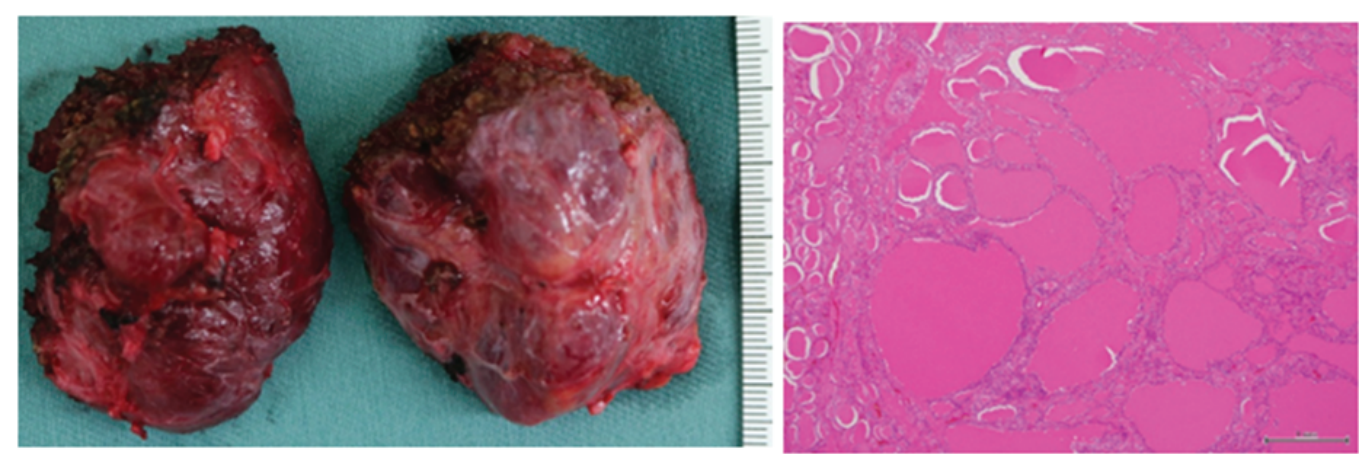

Figure 2: A resected specimen of the bilateral thyroid tumors (left). Postoperative histopathologic examination revealed follicular adenoma without malignant lesions or chronic thyroiditis (right).

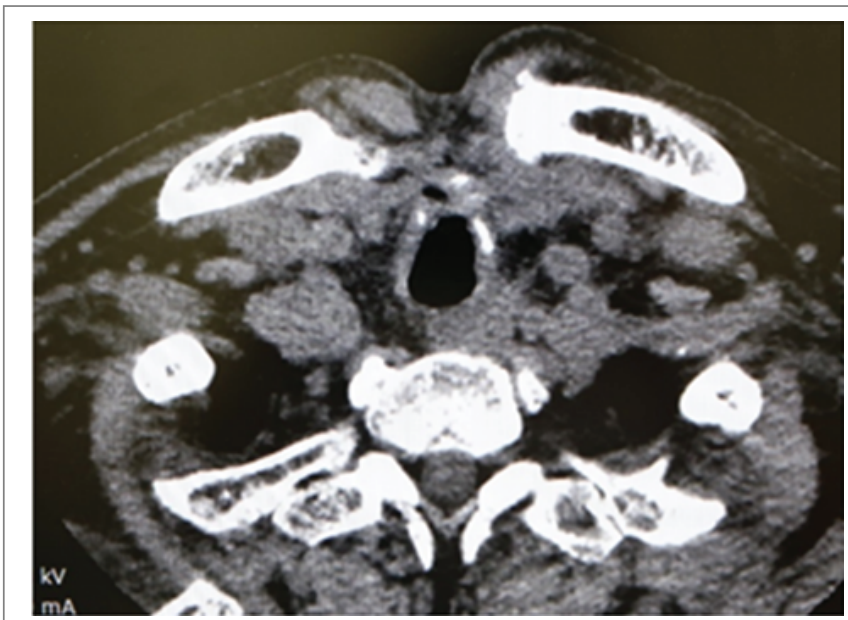

Figure 3: In the postoperative $\mathrm{CT}$, the tracheal stenosis had improved and the lumen had expanded to $15 \mathrm{~mm}$.

or, especially, postoperative complications. In the postoperative CT, tracheal stenosis had improved and widened to $15 \mathrm{~mm}$ from $7 \mathrm{~mm}$ in the lumen. Therefore, the tracheostoma was closed and there was no respiratory distress.

The postoperative pathologic diagnosis was follicular adenoma without cancer, lymphoma and chronic thyroiditis (Figure 2). In the postoperative blood samples, TSH, FT4and FT3 were within the normal range freeT3 $3.2 \mathrm{pg} / \mathrm{ml}$ (normal range: $2.4-4.5 \mathrm{pg} / \mathrm{ml}$ ), free T4 $1.3 \mathrm{ng} / \mathrm{dL}$ (normal range: $1.0-1.7 \mathrm{ng} / \mathrm{dL}$ ), $\mathrm{TSH} 3.08 \mu \mathrm{IU} / \mathrm{ml}$ (normal range: $0.56-4.3 \mu \mathrm{IU} / \mathrm{ml}$ ). The thyroglobulin was within the normal range of $26.80 \mathrm{ng} / \mathrm{ml}$ (normal range:0-33.70ng/ml).

\section{Discussion}

Alfonso A, et al. [5] reported that $67 \%$ of benign thyroid tumors with stenosis of the trachea coexisted with chronic thyroiditis. In our case, pathological examination was diagnosed as follicular adenoma and showed no chronic thyroiditis lesions. In the anti-thyroid autoantibodies, the microsome test and the thyroglobulin test were within the normal range. Yamada T, et al. [6] presented a case of adenomatous goiter with a fatal outcome caused by airway stenosis. Therefore, even benign thyroid tumors with advanced tracheal stenosis should be treated aggressively with surgery. Agarwal A, et al. [7] revealed that the incidence of tracheomalacia with large stroma was high even in benign thyroid tumors. Concerning the management of tracheomalacia, some hospitals performed tracheostomy and then inserted a T-tube into the trachea lumen after subtotal thyroidectomy $[8,9]$. In our case, we performed tracheotomy before subtotal thyroidectomy and observed no clinical findings of tracheomalacia postoperatively. Postoperative CT confirmed that the tracheal stenosis had improved and the lumen had spread to $15 \mathrm{~mm}$ from $7 \mathrm{~mm}$ (Figure 3). Therefore, the tracheostoma could be closed without respiratory distress. Yoshida Y, et al. [10] described that a tracheal lumen diameter 
over $8 \mathrm{~mm}$ in adults would cause no ventilation failure. In the present case, the patient underwent tracheotomy before amputation of his arm, which might have caused a morphological abnormality of the trachea after the surgery. Moreover, the intratracheal stimulation by oral intubation at the time of Achilles tendon surgery before visiting our hospital, in addition to the tracheal stenosis from the goiter, constricted the tracheal lumen to $7 \mathrm{~mm}$ causing breathing difficulty.

\section{Conclusion}

We present a case of a 75-year-old Japanese male patient with dyspnea due to a benign thyroid tumor. In the preoperative CT, a tracheal stenosis due to enlarged bilateral thyroid lobes had decreased the width of the lumen to $7 \mathrm{~mm}$. Subtotal thyroidectomy improved dyspnea. Postoperative histopathologic examination confirmed follicular adenoma without malignancy or chronic thyroiditis. On postoperative CT, the tracheal stenosis had improved and the width of the lumen had increased to $15 \mathrm{~mm}$ from $7 \mathrm{~mm}$. Our case suggests that a benign thyroid tumor with tracheal stenosis of the lumen has the possibility of causing dyspnea or death. Therefore, even benign thyroid tumors with advanced tracheal stenosis should be treated aggressively with surgery.

\section{Acknowledgements}

This work was supported in part by a Grant-in-Aid for Special Research in Subsidies for ordinary expenses of private schools from The Promotion and Mutual Aid Corporation for Private Schools of Japan. The authors thank Mr. Brent Bell for reading the manuscript.

\section{Contributions}

Takeshi Kusunoki: Diagnosis and therapy, composition of this manuscript. Ryo Wada: Pathological diagnosis.

\section{Conflicts of Interests}

The authors have no conflicts of interests to disclose.

\section{Consent for Publication}

We confirm the patient's anonymity and obtained consent for publication of the clinical findings, image examination and pathological examination.

\section{References}

1. Lawson L, Som ML, Biller HF (1977) Paillary adenocarcinpoma of the thyroid invading the upper air passages. Ann Otol Rhinol Larlyngol 86: 751-755.

2. Taura M, Kamizono K, Ejma M, Hara T, Nakano R, et al. (2010) Primary thyroid lymphoma: A report of three cases. Otologia Fukuoka 56: 243-246.

3. Kusunoki T, Homma H, Kidokoro Y, Yoshikawa A, Tanaka K, et al. (2020) Tracheal stenosis and recurrent nerve paralysis due to thyroid malignant lymphoma with huge chronic thyroiditis. Clin Pract 10: 1276.

4. Jauregui R, Liker ES, Bayley A (1972) Upper airway obstruction in euthyroid goiter. JAMA 238: 2163-2166.

5. Alfonso A, Chirstoudias G, Amaruddin Q, Herbsman H, Gardner B (1981) Tracheal or esophageal compression due to benign thyroid disease. Am J Surg 142: 350-354.

6. Yamada T, Hosokawa S, Oshima G, Izumi C, Matsuda S, et al. (2021) A case of adenomatous goiter with a fatal outcome caused by airway stenosis. Pract Otol 156: 128.

7. Agarwal A, Agarwal S, Tewari P, Gupta S, Chand G, et al. (2012) Clinicopathological profile, airway management, and outcome in huge multinodular goiters: An institutional experience from and endemic goier region. World J Surg 36: 755-760.

8. Bartolek D, Frick A (2012) Huge multinodular goiter with mid trachea obstruction: indication for fiberoptic intubation. Acta Clin Croat 51: 493-498.

9. Ayabe H, Kawahara K, Taawa Y, Tomita M (1992) Upper airway obstruction from a benign goiter. Surg Today 22: 88-90.

10. Yoshida $Y$, Toriya R, Uemura T, Matsuya H (1990) Training using T-tube for a child with functional inability of decanulation. Otologica Fukuoka 36: 219-222. 